\title{
Ruthenium-Catalyzed Asymmetric [2+2] Cycloaddition of Ynamides with Enones
}

Metal-Catalyzed Asymmetric Synthesis and Stereoselective

Reactions

\section{Key words}

[2+2] cycloaddition enones

ruthenium

\section{SYNFACGDinh} of the cing

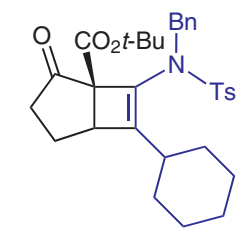

$97 \%$ yield $90 \%$ ee

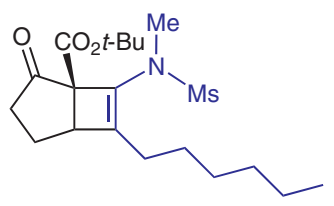

$94 \%$ yield $70 \%$ ee
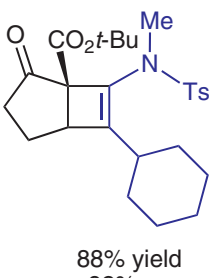

$92 \%$ ee

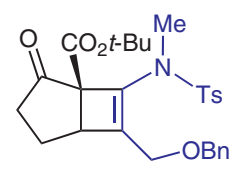

$60 \%$ yield
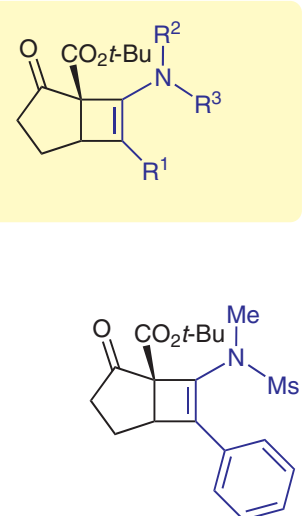

$69 \%$ yield

$83 \%$ ee

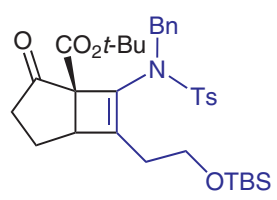

$86 \%$ yield

Catalyst preparation:

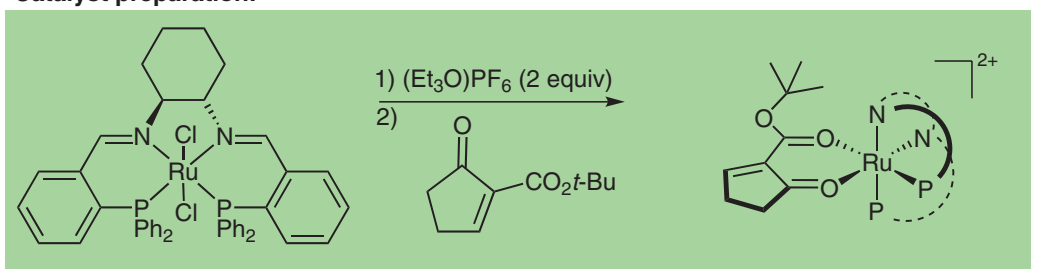

Significance: The chiral dicationic ruthenium complex catalyzes the asymmetric [2+2] cycloaddition of cyclic $\beta$-keto esters with ynamides. The reaction tolerates a wide range of substrates and generates an all-carbon quaternary stereogenic center in high yield and with high asymmetric induction.
Comment: Ynamides bearing an electron-deficient and an electron-donating group were found to be ideal substrates for this reaction due to the absence of an uncatalyzed background reaction at elevated temperatures. 